\title{
Thromboembolic Occlusion of Left Bracheal artery Protein-C and Protein-S Deficiency - A Case Report
}

MG Kibria ${ }^{1}$, GMM Hossain ${ }^{2}$, M Anisuzzaman ${ }^{1}$, MZ Haque ${ }^{1}$, KN Haque ${ }^{1}$, QA Azad ${ }^{2}$

${ }^{1}$ Department of Cardiac surgery, NICVD, Dhaka. ${ }^{2}$ Department of Vascular Surgery

Keywords:

Arterial

thrombo-

embolism,

Protein-C and

Protein-S

deficiency.

\begin{abstract}
:
Protein-C and Protein-S deficiency states are responsible for $3-5 \%$ (Protein-C) and 2-3\% (Protein-S) of patients with venous thrombosis. Some cases of arterial thrombosis have been reported. It occurs twice as often in female as in males. A 50 years old lady presented with acute severe pain in the left upper limb for 2 days. On investigation she was diagnosed as a case of bracheal artery thrombosis with Protein-C \& Protein-S deficiency. Bracheal thromboembolectomy was done and discharge her with life long warfarin therapy. In one year follow up the patient had no untoward event and INR done every month and warfarin is adjusted.
\end{abstract}

(Cardiovasc. j. 2010; 3(1):92-93)

\section{Introduction:}

Acute arm ischaemia accounts for one-fifth of all episodes of acute limb ischaemia. It occurs twice as often in female as in males. ${ }^{1}$ Protein-C and Protein-S deficiency states are responsible for 35\% (Protein-C) and 2-3\% (Protein-S) of patients with venous thrombosis. Some cases of arterial thrombosis have been reported. Diagnosis of Protein-C and Protein-S deficiency is made by Plasma Protein-C and Protein-S measurements. When the diagnosis is made in the setting of a thrombotic event, treatment consists of surgical intervention followed by anticoagulation, initially with heparin followed by life long oral anticoagulation (warfarin).

Most upper extrimity emboli lodge at the bifurcation of the bracheal artery into the radial and ulner vessel. ${ }^{2}$ Acute limb ischaemia is now often due to thrombotic disease. Embolic disease is commonly due to cardiac thrombus and cardiac arrhythmia. ${ }^{3}$ Recurrent venous thromboembolic disease is associated with reduced plasma level of the vit- $\mathrm{K}$ dependant factor, Protein- $\mathrm{C}$ in a small number of heterozygotes in affected families reported since 1981. Inheritence is autosomal. ${ }^{4}$

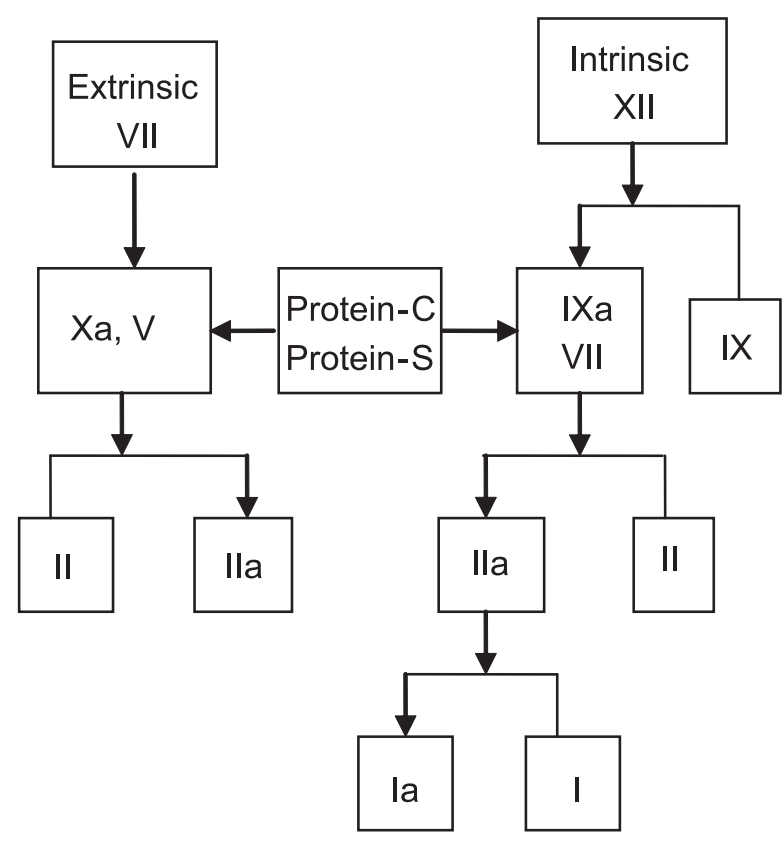

Fig.-1: Role of Protein-C and Protein-S in blood coagulation.

\section{Case report:}

A 50 years old lady with hypothyroidism, hypertensive, nondiabetic, osteoarthritic presented with severe pain in left upper limb for 2 days. On examination limb was cold,. but without color change. Her bracheal, radial, ulner pulses were absent. Duplex study shows thromboembolic 
complete occlusion of left bracheal artery. Carotid duplex was normal. X-ray neck excludes cervical rib. Echocardiogram showed no thrombus, vegetation or any other intracardiac mass. ECG within normal limit. Serum ANA/ANF and Anti ds-DNA antibody were negative.

Protein C (11.4\%) and protein S (30\%) levels were low.

She was operated and Fogarty emboleclomy done from the bracheal artery and distal vessels and flow was established and peroperative and postoperative heparinization done. Eight hours after embolectomy patient complaints blurring of vision. So we consulted with a neuro physician and an ophthalmologist. They advised MRI of brain and orbit that shows acute infarction in both occipital lobes (more remarkable on left side). Within 3 days of heparinization bluring of vision gradually improved. At the $7^{\text {th }}$ postoperative day patient was discharged with life long oral anticoagulant warfarin therapy to maintain INR around 2.5-3. After one year follow up, patient was alright and revealed satisfactory pulses in all distal vessels and good sensory \& motor activity of the limb.

\section{Discussion:}

The term "hypercoagulable state" is generally used to denote any condition in which the normal ballance between clotting and anticlotting mechanisms becomes altered in such an extent that the patient is predisposed to thrombus formation. Among the numerous conditions that can lead to a hypercoagulable state, Protein-C and $\mathrm{S}$ deficiencies have been frequently described. ${ }^{5}$

Acute arm ischaemia accounts for one-fifth of all episodes of acute limb ischaemia. It occurs twice as often in females as in males. Bracheal embolectomy is the most common treatment. After successful bracheal embolectomy, $95 \%$ of patients are symptom free. ${ }^{6}$

Fogarty embolectomy catheter may be used for acute thromboembolism. In this case patient was managed conservatively in Chittagong then shifted to Dhaka and then fogarty embolectomy done. Embolization recurs after successful embolectomy in about one third of the patients if systemic anticoagulation is not used. It may even recur in about $11 \%$ of cases after oral anticoagulation. Occasionally the hand continues to appear ischaemic after successful embolectomy. This persistent ischaemia is caused either by an unrecognized inflow lession or by emolization to the digital arteries that has been occuring over an extended period. In this patient an arch aortogram with selective view of the affected arm should be performed immediately after operation. Any lesion in the subclavian artery or innominate artery can be treated by angioplasty or stenting. ${ }^{7}$

\section{References:}

1. Hoque MR, Hussain S, Alauddin M, Rahman Z (2009); Successful treatment of subclavian artery thrombosis with gangrene of fingers- a case report. University heart Journal. 5(1): 44-46

2. Henke PK, Schmaier A, Wakefield TW. Vascular thrombosis due to hyper coagulable states. In Cronenwett JL, Gloviczki P, Johnston KW. Eds. Rutherford Vascular Surgery $6^{\mathrm{h}} \mathrm{ed}$, Philadelphia Elsevier, Saunders. 2005: 569-571.

3. Camm AJ and Bunce NH, Cardiovascular disease. In Kumar P, Clark M, Eds. Kumar and Clark clinical Medicine $\mathrm{ti}^{\mathrm{th}} \mathrm{ed}$, Spain. Elsevier saunders. 2005: 867

4. Firkin F, Chesterman C, Penington D \& Rush B. Thrombosis: Clinical features and management. In: de Gruchy's clinical haematology in medical practice $5^{\text {th }}$ ed, Berlin. Blackwell Science 1989: 457.

5. Cho YP, kwon T-W, Ahn J-H, Kang GH, Han MS, Kim Y H, Kwak JH and Lee SG. Prolein C and/or S deficiency presenting as peripheral arterial insufficiency, The British Journal of Radiology, 2005; 78:603.

6. Hernandez- Richter T, Angele MK and HelmbergerT, Acute ischaemia of the upper extremity: Longterm result following thromboembolectomy with fogarty catheter, langenbecks Arch Surg, 2001; 386:261.

7. Stonebridge PA, Clason AE and Duncan AJ, Acute ischaemia of the upper limb compared with acute lower limb ischaemia, a 5 year review, B J Surg 1989; 76:515. 